\title{
Analisis Pasar Wisatawan Nusantara di Candi Borobudur
}

\author{
Cecep Ucu Rakhman \\ Sekolah Tinggi Pariwisata Bandung, Indonesia \\ Email: cecep.u.r@gmail.com
}

\begin{abstract}
This is a marketing research in the tourism sector that discusses the market segmentation of domestic tourists (wisnus) in Borobudur Temple. This study analyzed the profile of the wisnus using quantitative research. Methods of data collection were conducted with questionnaires, field observations, and documentation studies. The results showed that tourists who visited Borobudur Temple mostly came from outside the province (62\%) and within the province (38\%). When viewed from the provincial origin, then the five largest provinces are domestic tourists from Central Java Province of 38\%, while respondents who come from the West Java Province of $13 \%$. Then the respondents from D.l. Yogyakarta with 10\%, then East Java Province 9 and DKI Jakarta 9\%. Respondents who visited Borobudur Temple were 15-24 years old (36\%), male (58\%), married (52\%), graduated from diploma (46\%), still in student status (27\%), Revenue per month $<$ Rp. 2,000, 000.00 (52\%). The majority of respondents have preference type DTW historic sites (52\%), preferences for recreational activities (81\%), art and culture (53\%), friend / family sources (53\%), family (52\%), had no constraints (43\%), day preference on national holidays (39\%), in the morning (57\%), duration of $1-3$ hours (65\%), visitfrequency 1 times (80\%), average / moderate price perception (75\%), rate of Borobudur temple at good enough level (58\%), and have hope for improvement of DTW (45\%) location arrangement. Spending at DTW> Rp. 50.000,00 (28\%), total expenses during trip <Rp. 200.000,00 (32\%), the largest share of expenditure is located on transportation (34\%), using land transportation (86\%) and air (13\%), visiting reason because Borobudur Temple has artistic and cultural value (38\%), preference of stay in other hotels / inns $(36 \%)$, visit planning $<1$ week earlier $(65 \%)$, recommend Borobudur Temple $(96 \%)$, and have a return visit (97\%). In comparison of markets within and outside the province, the source of information from friends /family $(62 \%)$ is preferred by the market within the province. Outside provincial markets (85\%) have motivational preferences of visiting for recreation and leisure. The average income of domestic tourists in the province is $\mathrm{Rp}$. 3.138.298 Meanwhile, the average income of tourists outside the province is Rp.3.750.000. Expenditure at Borobudur Temple for respondents in the province is Rp.194.681, - meanwhile for out ofprovince is Rp.202.885. 000, -. Travelers from within the province have an average total of travel expenses ofRp.606.383 and outside the province ofRp.1.264.744. Nusantara tourists in the province have purchasing power of $19 \%$ of income per month while from outside the province have purchasing power of $34 \%$ of tourist income per month. For the largest expenditure during the trip is on transportation, tourists outside the province has a magnitude of $36 \%$ and tourists in the province of $32 \%$. For the category recommend, tourists outside the province have $95 \%$ and tourists in the province of $98 \%$. The appraisal of tourism facilities is at a sufficiently good level with a value of 3.50, all price aspects considered to have a range between 3.25 - 3.46 infrastructure components and promotion is quite good with an average score of 3.55.
\end{abstract}

Keywords: Market Profile, Segmentation, Tourist Archipelago, Borobudur Temple.

\begin{abstract}
Abstrak
Penelitian ini mengenai pemasaran di sektor pariwisata yang membahas segmentasi pasar wisatawan domestik (wisnus) di Candi Borobudur. Penelitian ini menganalisis profil Wisnus menggunakan penelitian kuantitatif. Metode pengumpulan data dilakukan dengan kuesioner, observasi lapangan, dan studi dokumentasi. Hasil penelitian menunjukkan bahwa wisatawan yang mengunjungi Candi Borobudur sebagian besar berasal dari luar provinsi (62\%) dan di dalam provinsi (38\%). Jika dilihat dari asal provinsi, maka lima provinsi terbesar adalah wisatawan domestik dari Provinsi Jawa Tengah sebesar 38\%, sedangkan responden yang berasal dari Provinsi Jawa Barat sebesar 13\%. Kemudian responden dari D.l. Yogyakarta dengan 10\%, kemudian Provinsi Jawa Timur 9 dan DKI Jakarta 9\%. Responden yang mengunjungi Candi Borobudur berusia 15-24 tahun (36\%), pria (58\%), menikah (52\%), lulus diploma (46\%), masih berstatus pelajar (27\%), Penghasilan per
\end{abstract}


bulan $<$ Rp . 2.000.000,00 (52\%). Mayoritas responden memiliki preferensi jenis situs bersejarah DTW (52\%), preferensi untuk kegiatan rekreasi (81\%), seni dan budaya (53\%), sumber teman / keluarga (53\%), keluarga (52\%), tidak memiliki kendala (43\%), preferensi hari pada hari libur nasional (39\%), di pagi hari (57\%), durasi l -3 jam (65\%), frekuensi kunjungan 1 kali (80\%), persepsi harga rata-rata / sedang (75\%) ), tingkat candi Borobudur pada tingkat yang cukup baik (58\%), dan memiliki harapan untuk peningkatan pengaturan lokasi DTW (45\%). Pengeluaran di DTW $>$ Rp. $50.000,00$ (28\%), total biaya selama perjalanan <Rp. 200.000,00 (32\%), bagian terbesar dari pengeluaran terletak pada transportasi (34\%), menggunakan transportasi darat (86\%) dan udara (13\%), alasan berkunjung karena Candi Borobudur memiliki nilai seni dan budaya (38\%) , preferensi menginap di hotel / losmen lain (36\%), perencanaan kunjungan $<1$ minggu sebelumnya (65\%), merekomendasikan Candi Borobudur (96\%), dan mendapat kunjungan kembali (97\%). Dalam perbandingan pasar di dalam dan di luar provinsi, sumber informasi dari teman / keluarga (62\%) lebih disukai oleh pasar di dalam provinsi. Pasar di luar provinsi (85\%) memiliki preferensi motivasi untuk berkunjung untuk rekreasi dan rekreasi. Pendapatan rata-rata wisatawan domestik di provinsi ini adalah Rp. 3.138.298 Sementara itu, pendapatan rata-rata wisatawan di luar provinsi adalah Rp3.750.000. Pengeluaran di Candi Borobudur untuk responden di provinsi adalah Rp.194.681, sementara untuk di luar proses adalah Rp.202.885. 000, -. Wisatawan dari dalam provinsi memiliki total rata-rata biaya perjalanan sebesar Rp.606.383 dan di luar provinsi sebesar Rp1.264.744. Wisatawan nusantara di provinsi ini memiliki daya beli $19 \%$ dari pendapatan per bulan sedangkan dari luar provinsi memiliki daya beli $34 \%$ dari pendapatan wisatawan per bulan. Untuk pengeluaran terbesar selama perjalanan adalah untuk transportasi, wisatawan di luar provinsi memiliki besaran $36 \%$ dan wisatawan di provinsi 32\%. Untuk kategori rekomendasikan, wisatawan di luar provinsi memiliki 95\% dan wisatawan di provinsi 98\%. Penilaian fasilitas pariwisata berada pada tingkat yang cukup baik dengan nilai 3,50, semua aspek harga dianggap memiliki kisaran antara 3,25 - 3,46 komponen infrastruktur dan promosi yang cukup baik dengan skor rata-rata 3,55..

Kata Kunci: Profil Pasar, Segmentasi, Wisatawan Nusantara, Candi Borobudur.

\section{A. PENDAHULUAN}

Penelitian Analisis Pasar Wisatawan Nusantara di Candi Borobudur ini merupakan bagian penting dari upaya penetapan strategi pemasaran wisata budaya yang lebih efektif dan merupakan upaya untuk memahami karakteristik dan kcinginan pasar, sehingga bisa menjadi referensi penting di dalam memasarkan produk-produk wisata budaya dan di dalam menyusun program promosinya. Untuk mendukung pelaksanaan analisis agar mendapat hasil yang optimal, make dilakukan observasi langsung ke lokus penelitian. Survey dilakukan dengan metodepenyebaran kuesioner dan wawancara dan hasilnya dianalisis dengan metode kuantitatif serta data pendukung lainnya yang diperoleh dari berba,ai sumber dan referensi baik off-line maupun on-line.

Para pemangku kepentingan kepariwisataan kawasan wisata Candi Borobudur belum tepat dalam memahami bagaimana profil dan apa yang ada di benak wisatawan nusantara, khususnya wisatawan nusantara yang berkunjung ke daya tank wisata budaya. Oleh karena itu perlu dilakukan pemahaman yang lebih mendalam terhadap kebutuhan, keinginan, dan harapan dari wisatawan nusantara tersebut. Dad uraian tersebut, maka penulis merasa perlu untuk melakukan penelitian yang berjudul Analisis Pasar Wisatawan Nusantara di Candi Borobudur dengan rumusan masalah

\section{"Bagaimanakah Profil Pasar Wisatawan Nusanatra di Candi Borobudur?"}

Tujuan dari penelitian ini adalah (1) MenQindentifikasi profil wisatawan nusantara di Candi Borobudur yang mempunyai daya tank wisata budaya yang menonjol di Indonesia. Profil yang dicari meliputi: (a) Profil geografis; (b) Profil demografis; (c) Profil Psikografis; dan (d) Profil Perilaku, serta Profil Pasar Dalam dan Luar Provinsi; serta (2) Mengidenttifikasi penilaian kepuasan wisatawan nusantara terhadap fasilitas di Candi Borobudur.

Sasaran dad penelitian ini adalah (1) Terindentifikasinya profil wisatawan nusantara di Candi Borobuduryang mempunyai daya tank wisata budaya yang menonjol di Indonesia. Maksud penelitian 
ini adalah mengumpulkan data-data untuk memperoleh profil pasar wisatawan nusantara di Candi Borobudur secara komprehensif dengan mempertimbanskan semua aspek terkait. seperti: aspek geografi, demografi, psikografi dan behavioral (perilaku), serta pasar dalam dan luar provinsi; serta (2) Terindentifikasinya penilaian kepuasan wisatawan nusantara terhadap fasilitas di Candi Borobudur.

Manfaat dari penelitian ini bagi para pemangku kepentingan. Bagi pihak Akademisi supaya terjadi peningkatan kualitas dan kuantitas penelitian mengenai Candi Borobudur. Bagi pihak Swasta (Bisnis)/Pihak Pengelola: agar pengembanaan pemasaran Candi Borobudur lebih efektif dan efisien. Bagi pihak Pemerintah: supaya terjadi peningkatan koordinasi dengan pengelola. Dan bagi pihak Masyarakat: agar terjadi peningkatan kualitas kenyamanan dan pelayanan di Candi Borobudur.

\section{Kerangka Pemikiran}

Penelitian ini berawal dari kerangka pemikiran bahwa wisatawan nusantara yang mengunjungi daya tarik wisata budaya masih sedikit apabila dibandingkan dengan daya tarik wisata alam dan buatan. Akan tetapi salah satu daya tarik wisata budaya yang, banyak dikunjungi oleh wisatawan nusantara adalah Candi Borobudur. Oleh karena itu penulis merasa penting untuk menganalisis wisatawan nusantara yang datang berkunjung ke Candi Borobudur berdasarkan aspek geografis, demografis, psikografis, dan perilaku.

Selain menganalisis dari aspek segmentasi, penelitian ini juga menganalisis kepuasan wisatawan nusantara berdasarkan fasilitas yang ada, harga, infrastruktur dan promosi yang telah dilakukan. Hasil dari penelitian ini akan mendapatkan profil wisatawan nusantara yang datang ke Candi Borobudur serta saran yang dapat diberikan bagi pengembangan dan kemajuan Candi Borobudur pada khususnya, dan bagi pengembangan dan kemajuan daya tarik wisata budaya pada umunmya. Untuk dapat memahami lebih jelas tentang penelitian ini, maka telah dibuat kerangka pemikiran dalam bentuk bagan seperti yang dapat dilihat pada gambar 1 berikut.

\author{
Aspek Geografis \\ Aspek Demogrdfis \\ Aspek Psikografis \\ Aspek Perilaku
}

\author{
Fa as DTW \\ Harga \\ Infrastruktur
}

\section{Gambar 1 Kerangka Pemikiran}

\section{B. METODE PENELITIAN}

Metode penelitian yang digunakan dalam penelitian ini adalah metode penelitian kuantitatif. Penelitian kuantitatif ini menggunakan metode penulisan deskriptif dan cenderung menggunakan analisis dengan pendekatan deduktif. Pendekatan deduktif adalah pendekatan yang menggunakan logika untuk menarik satu atau lebih kesimpulan berdasarkan premis yang diberikan. Metode berpikir deduktif adalah metode yang menerapkan hal-hal yang umum terlebih dahulu untuk seterusnya dihubunEkan dalam bagian-bagiannya yang khusus. Dalam penelitian ini metode yang digunakan adalah metode deskriptif. Metode ini adalah metode yang didasarkan pada pemecahan masalah berdasarkan fakta yang ada. Data yang diperoleh dijelaskan dan selanjutnya dianalisa 
berdasarkan teori yang ada kemudian ditarik kesimpulannya (Surakhmad, 1985:140). Metode deskriptif digunakan untuk menggambarkan profil wisatawan budaya nusantara. Gambaran umum profil mencakup aspek pennintaan dan penawaran pasar wisata budaya nusantara.

Metode deskriptif adalah penelitian yang dirancang untuk memperoleh informasi tentang status suatu gejala saat penelitian dilakukan dengan cara survey, yaitu studi pengumpulan data yang relatif terbatas dari kasus-kasus yang relatif besar jumlahnya. Tujuannya adalah untuk mengumpulkan informasi tentang variabel berdasarkan ruang lingkupnya (Sensus atau survay sampel) dan subyeknya (hal nyata atau tidak nyata).

\section{Observasi}

Jenis penelitian yang dilakukan dalam teknik ini diantaranya pengamatan, dan penilaian terhadap kondisi pasar wisatawan nusantara, dilakukan langsung pada lokasi yaitu Candi Borobudur dan dimaksudkan untuk mengumpulkan data yang dibutuhkan dengan menggunakan alat kumpul data berupa daftar periksa (Check list).

\section{Penyebaran Kuesioner}

Penyebaran kuesioner dilakukan kepada wisatawan, dengan maksud untuk mengetahui pendapat dari setiap pengunjung mengenai atraksi yang ada di daya tank wisata Candi Borobudur, aktivitas, dan fasilitas yang ada di kawasan tersebut.

Dalam penelitian ini digunakan non probability sampling yaitu teknik sampling yang tidak memberi peluang/kesempatan yang sama bagi setiap unsur atau bagi anggota populasi untuk dipilih menjadi sampel (Sugiyono, 1997:61). Teknik sampling ini meliputi purposive sampling yaitu teknik penentuan sampel untuk tujuan tertentu saja (Sugiyono, 1997:62) dan sampling aksidental yaitu teknik penentuan sampel berdasarkan siapa saja yang secara kebetulan bertemu dengan peneliti dan dapat digunakan sebagai sampel yang dinilai sebagai sumber data (Sugiyono, 1997:62). Teknik sampling yang digunakan dalam penelitian ini ialah sampling aksidental.

Segmentasi merupakan pekerjaan yang berdasarkan kepada penelitian yang memiliki beberapa langkah. Penelitian tentang segmentasi pasar boleh menggunakan metode Simple Demographics atau Complex Demographic dan Multivariate. "Segmenting markets is a research-based exercise with several stages. These apply irrespective of whether the method used is simple demographics or complex and multivariate (Kotler, dkk, 2005: 414).

\section{Populasi dan Sampel}

Populasi penelitian ini adalah wisatawan nusantara yang berkmnjung ke Candi Borobudur pada bulan Juli 2017. Sedangkan sampel penelitian ini mengacu kepada pendapat Kotler, dkk (2005:414), bahwa minimal hams memiliki 100 responden dengan menggunakan kuesioner, maka penelitian ini berusaha mendapatkan responden melalui kuesioner sebanyak-sebanyaknya dengan batas minimal 100 responden dengan bentuk sampling stratified (sampling berlapis).

Bentuk sampling ini termasuk dalam teknik sampling probabilitas. Bentuk sampling berlapis adalah bentuk sampling random dimana populai dibagi dalam kelompok-kelompok yang disebut strata. Dalam penelitian ini, strata terbagi dua, yaitu kelompok wisatawan mancanegara (wisman) dan kelompok wisatawan nusantara (wisnus). Yang dijadikan sampling hanya kelompok wisnus. Dengan keterbatasan waktu yang diberikan selama lebih kurang 7 hari pada tanggal 10- 16 Juli 2017 (5 hari efektif di lapangan), akhirnya didapatkan sampel sebanyak 125 responden. 


\section{HASIL DAN ANALISIS}

\section{Profil Pasar Umum}

Dari data aspek geografis dapat kita ketahui bahwa ada sebanyak 21 provinsi asal wisatawan nusantara yang datang berkunjung ke Candi Borobudur, dari Aceh hinYga Papua. Hal ini menandakan Candi Borobudur menarik minat sebagian besar wisatawan nusantara yang ada di Indonesia. Untuk lima besar asal provinsi wisatawan nusantara yang datang seluruhnya berasal dari Pulau Jawa, yaitu Provinsi Jawa Tenaah, Jawa Barat, D.I. Yogyakarta, DKI Jakarta, dan Jawa Timur. Dari data provinsi asal maka dapat dibuat strategi pemasaran yang fokus pada pemasaran ke wisatawan nusantara di Pulau Jawa yang bekeijasama dengan biro perjalanan wisata untuk menawarkan paket wisata ke Candi Borobudur dengan menggunakan transportasi darat.

Dari data aspek demografis dapat kita ketahui bahwa mayoritas usia responden 15-24 tahun (36\%) dan 25-34 tahun (33\%) atau dalam kategori remaja dan pemuda Pendidikan terakhir DiplomalSarjana (46\%) dan SMA (45\%) dengan pekeijaan sebagian besar adalah pelajar/mahasiswa (27\%) serta karyawan (22\%). Mayoritas pendapatan kurantr dari Rp.2.000.000 (52\%) dan Rp.2.000.000 - Rp.5.000.000 (32\%). Dui data aspek demografis dapat kita buat strategi pemasaran yang fokus kepada para remaja dan pemuda yang sebagian besar adalah pelajar/mahasiswa serta karyawan. Pihak Pengelola Candi Borobudur dapat melakukan roadshow dan kerjasama dengan pihak sekolahiperguruan tinggi dan perusahan-perusahaan untuk membuat paket-paket wisata ke Candi Borobudur.

Dari data aspek Psikografis dapat kita buat strategi pemasaran yang fokus melalui kekuatan word of mouth to mouth promotion dan media online. Jadi agar promosi dari mulut ke mulut pengunjung berjalan efektif, maka pihak pengelola harus dapat memberikan pelayanan yang melebihi harapan dari pengunjung (beyond the expaction) atau yang biasa dikenal dengan pelayanan prima. Selain itu strategi yang lain adalah dapat dibuat atau ditampilkan lebih banyak ragam atraksi pada khusus hari libur besar nasional sejak pagi hari sehingga wisatawan nusantara yang datang dapat meluangkan waktunya lebih adri 3 jam dan membelanjakan uangnya lebih banyak di Candi Borobudur. Dapat dibuat proram diskon bagi wisatawan nusantara yang pernah mengunjungi Kawasan Cando Borobudur untuk kunjungan ke-2, ke-3 dan seterusnya, agar lebih banyak lagi repeater wisatawan nusantara.

Dari data aspek Perilaku dapat kita ketahui bahwa pengcluaran wisatawan nusantara masih relatif kecil baik itu pengeluaran di kawasan Candi Borobudur maupun total pengeluaran selama perjalanan. Khusus untuk di Kawasan Candi Borobudur diberlakukan standard harga makanan dan minuman yang tidak terl alu $\mathrm{j}$ auh bedanya dengan yang ada di luar Kawasan. Selain itu kualitas cinderamata/souvenir juga ditingkatkan dan harga disesuaikan dengan kualitas.

\section{Profil Pasar Asal Dalam dan Luar Provinsi}

Untuk memudahkan dalam melihat secara keseluruhan dari profil pasar dalam dan luar provinsi dan menganalisisnya, maka peneliti merekap data persentase terbesar pertama dan kedua dalam bentuk tabel 1 .

Dari data profil pasar dalam dan luar provinsi dapat kita ketahui bahwa purchasing power pasar dari luar provinsi lebih besar dari dalam provinsi. Oleh karena itu promosi dapat difokuskan kepada pasar dai luar provinsi karena terbukti memberikan pemasukan yang lebih kepada Kawasan Wisata Candi Borobudur. 
Tabel 1. Persentase Terbesar I dan 11 Profil Pasar Dalam dan Luar Provinsi

\begin{tabular}{|c|c|c|}
\hline \multirow[t]{2}{*}{$\mathrm{T} \mathrm{m} n \mathrm{mi}$} & \multicolumn{2}{|r|}{ Asal } \\
\hline & Ijalarn Provinsi & Luar Provinsi \\
\hline 1. Sumber Informasi & $\begin{array}{l}\text { Teman/keluarga }(62 \%) \\
\text { \& Media online }(21 \%)\end{array}$ & $\begin{array}{l}\text { Teman/keluarga (47\%) \& Media } \\
\text { online ( } 22 \%) \text {, Media elektronik }\end{array}$ \\
\hline 2. Motivasi Berkunjung & $\begin{array}{l}\text { Rekreasi/bersantai } \\
\text { (74\%) \& }\end{array}$ & $\begin{array}{c}\text { Rekreasi/bersantai (85\%) \& } \\
\text { Studi/penelitian (10\%) }\end{array}$ \\
\hline 3. Pendapatan per Bulan & $\begin{array}{c}\text { Rp.2.000.000 (60\%) \& } \\
\text { Rp.2.000.000- } \\
\text { Rp.5.000.000 (30\%) }\end{array}$ & $\begin{array}{c}<\text { Rp. } 2.000 .000(47 \%) \& \\
\text { Rp.2.000.000- Rp.5.000.000 } \\
(33 \%)\end{array}$ \\
\hline 4. Pengeluaran di DTW & $\begin{array}{c}<\text { Rp.50.000 (34\%) \& } \\
\text { Rp.101.000- } \\
\text { Rp.200.000 (26\%) }\end{array}$ & $\begin{array}{c}<\text { Rp.50.000 (24\%) \& Rp.101.000 - } \\
\text { Rp.200.000 (27\%) }\end{array}$ \\
\hline $\begin{array}{l}\text { 5. Total pengeluaran selama } \\
\text { penjalanan }\end{array}$ & $\begin{array}{c}\text { Rp.200.000 (45\%) \& } \\
\text { Rp.201.000- } \\
\text { Rp.500.000 (28\%) }\end{array}$ & $\begin{array}{c}<\text { Rp.200.000 (24\%) \& Rp.201.000 } \\
\text {-Rp.500.000 (27\%) }\end{array}$ \\
\hline $\begin{array}{l}\text { 6. Rata-rata pendapatan per } \\
\text { Bulan }\end{array}$ & Rp.3.138.298 & Rp.3.750.000 \\
\hline $\begin{array}{l}\text { 7. Rata-rata Total } \\
\text { Pengeluaran di Perjalanan }\end{array}$ & Rp.606.383 & Rp.1.264.744 \\
\hline 8. Purchasing Power & $19 \%$ & $34 \%$ \\
\hline 9. Pengeluaran Terbesar & $\begin{array}{l}\text { Transportasi }(32 \%) \& \\
\text { Souvenir/cinderamata }\end{array}$ & $\begin{array}{c}\text { Transportasi }(36 \%) \& \text { Akomodasi } \\
(29 \%)\end{array}$ \\
\hline Merekomendasikan & Ya $(98 \%)$ & Ya (95\%) \\
\hline
\end{tabular}

\section{Penilaian Kepuasan Wisnus}

Analisis kepuasan wisnus terhadap fasilitas DTW membahas mengenai bcberapa variabel yang terkait dengan DTW, yaitu kondisi ibadah, toilet/MCK, pelayanan informasi, keamanan, kesehatan, dan perdagangan, seperti yang dapat dilihat pada tabel 6 berikut ini.

Tabel 2. Penilaian Fasilitas Candi Borobudur

\begin{tabular}{clc}
\hline & \multicolumn{1}{c}{ Indikator } & Penilaian \\
\hline 1. & Kondisi Candi Borobudur & 3.83 \\
\hline 2. & Fasilitas Pelayanan Informasi & 3.69 \\
\hline 3. & Fasilitas Ibadah & 3.64 \\
\hline 4. & Fasilitas Pelayanan Keamanan & 3.59 \\
\hline 5. & Fasilitas Pelayanan Kesehatan & 3.45 \\
\hline 6. & Keberagaman Atraksi & 3.42 \\
\hline 7. & Pusat Cinderamata dan Kuliner & 3.33 \\
\hline 8. & Fasilitas Toilet/MCK & 3.30 \\
\hline 9. & Fasilitas Parkir & 3.26 \\
\hline & & $\ldots 5(\mathrm{t}$ \\
\hline
\end{tabular}

Pada Tabel 2 dapat dilihat bahwa nilai tertinggi ada pada komponen kondisi Candi Borobudur dengan nilai sebesar 3,83 diikuti oleh komponen fasilitas pelayanan informasi sebesar 3,69. Untuk urutan ketiga ada komponen fasilitas ibadah dengan nilai 3,64. Dan keempat yang masih mempunyai nilai di atas rata-rata adalah Fasilitas pelayanan keamanan. Penilaian keseluruhan dari komponen penyelenggaraan Candi Borobudur tersebut mendapatkan nilai rata- rata sebesar 3,50 yang berarti

84 Jurnal Kepariwisataan: Destinasi, Hospitalitas dan Perjalanan, Volume 3 Nomor 2, 2019: 79-87 
secara keseluruhan komponen fasilitas Candi Borobudur yang dianalisis mendapatkan nilai sedang (cuk-up).

Sementara itu ada lima kriteria yang perlu mendapat perhatian serius karena mempunyai nilai di bawah nilai rata-rata. Kriteria pertama yang hams mendapat perhatian adalah fasilitas kesehatan $(3,45)$, kedua keberagaman atraksi $(3,42)$, kriteria ketiga adalah pusat cinderamata dan kuliner $(3,33)$, diikuti fasilitas toilet/MCK $(3,30)$, dan yang terendah adalah fasilitas parkir $(3,26)$.

Kelima kriteria yang mempunyai nilai di bawah rata-rata nilai kepuasan tersebut hams menjadi perhatian bagi pengelola Candi Borobudur untuk dapat meningkatkan kembali kualitas fasilitasnya. Bagi komponen yang sudah dirasa baik maka tents dipertahankan dan juga untuk komponen yang dirasa tidak baik penilaiannya dapat ditingkatkan kembali demi tercapainya kepuasan wisatawan saat berkunjung kembali ke Candi Borobudur tersebut pada waktu yang akan datang. Harga Tiket Masuk

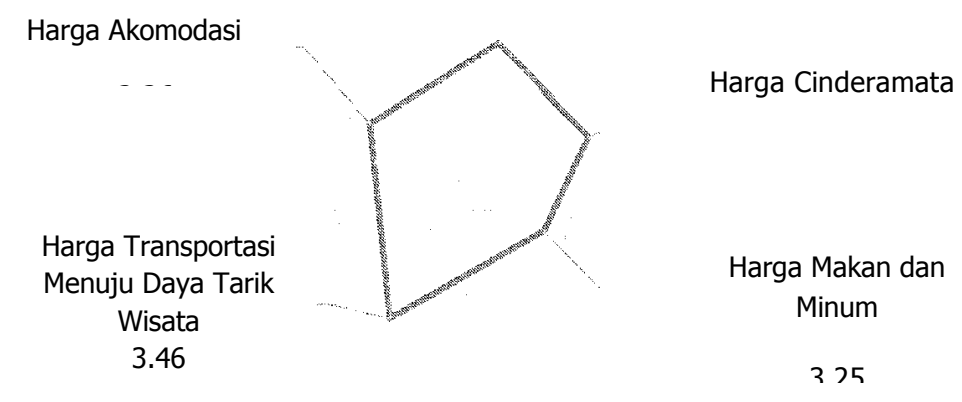

\section{Gambar 2 Komponen Harga}

Dari Gambar 2 dapat diketahui bahwa nilai tertinggi ada pada komponen harga transportasi menuju daya tarik wisata $(3,46)$ diikuti oleh komponen harga akomodasi $(3,36)$. Untuk urutan ketiga ada komponen harga tiket masuk $(3,34)$. Penilaian keseluruhan dari komponen harga di Candi Borobudur tersebut mendapatkan nilai rata-rata sebesar 3,34 yang berarti secara keseluruhan komponen harga di Candi Borobudur yang dianalisis mendapatkan nilai sedang (cukup).

Selain itu untuk dua nilai terendah yang mempunyai nilai di bawah rata-rata yaitu pada komponen harga cinderamata $(3,28)$, dan yang paling rendah adalah pada komponen harga makan dan minum $(3,25)$. Untuk harga cinderamata hams disesuaikan dengan kualitas yang ada. Semakin kualitasnya bagus semakin harganya semakin tinggi, akan tetapi apabila kualitasnya semakin kurang, maka sudah sewajarnya apabila harganya juga semakin rendah. Sedangkan untuk harga makan dan minum seharusnya harga-harganya tidak jauh beda dengan harga-harga makan dan minum di luar Candi Borobudur.

Tabel 3. Penilaian Infrastruktur dan Promosi

\begin{tabular}{|c|c|c|}
\hline No & Indikator & Penilaian \\
\hline 1 & Publikasi Informasi Daya Tarik Wisata & 3.82 \\
\hline 2 & Ketersediaan Penunjuk Arah Menuju Daya Tarik & 3.66 \\
\hline 3 & Tingkat Kebersihan Daya Tarik Wisata & 3.58 \\
\hline 4 & Kondisi Jalan & 3.55 \\
\hline \multirow[t]{2}{*}{5} & Tingkat Kelancaran Lalu Lintas Menuju Candi & 3.42 \\
\hline & $\bullet$ Rata-rata & $3: 55$ \\
\hline
\end{tabular}

Pada Tabel 3 meneenai penilaian Infrastruktur dan Promosi dapat diketahui bahwa nilai tertinggi ada pada komponen publikasi informasi daya tarik wisata $(3,82)$ diikuti oleh komponen ketersediaan penunjuk arah menuju daya tarik wisata $(3,66)$. Untuk urutan ketiga ada komponen tingkat kebersihan 
daya tarik wisata $(3,58)$, dan urutan keempat ada pada komponen kondisi jalan $(3,55)$. Penilaian keseluruhan dari komponen Infrastruktur dan promosi Candi Borobudur tersebut mendapatkan nilai rata-rata sebesar 3,55 yang berarti secara keseluruhan komponen Infrastruktur dan promosi Candi Borobudur yang dianalisis mendapatkan nilai cukup (sedang).

Sementara itu untuk nilai terendah yang berada di bawah nilai rata-rata yaitu pada tingkat kelancaran lalu lintas menuju daya tarik wisata $(3,42)$. Oleh karena itu pihak pengelola Candi Borobudur hams memperhatikan tingkat kelancaran lalu lintas menuju Candi Borobudur dengan bekerja sama dengan pihak-pihak terkait yang berwenang dalam mengatur lalu lintas jalan raya seperti dinas perhubungan dan pihak kepolisian.

\section{SIMPULAN}

Menurut data secara akumulatif tahun 2016 pada Candi Borobudur mencatatkan angka jumlah perjalanan sebesar 362.125 wisnus, meningkat $9 \%$ dari tahun 2015. Sementara itu jumlah perjalanan wisnus yang berkunjung ke Candi Borobudur pada semester I tahun 2017 (Januari — Juni 2017), tercatat angka kunjungan sebesar 1.269.867 menurun 24\% dari semester pertama pada tahun 2016. Profil pasar merupakan salah satu kunci kesuksesan sebuah daya tank wisata agar berkelanjutan dan memberikan dampak ekonomi yang positif terhadap masyarakat. Selain itu, keakuratan data mengenai profil pasar juga sebagai penunjang untuk memberikan strategi yang tepat. Berikut adalah profil pasar wisatawan nusantara secara aktual yang mengunjungi Candi Borobudur, Jawa Tengah.

\section{DAFTAR REFERENSI}

Badan Pusat Statistik, 2008. Pengertian Wisatawan Nusantara. Jakarta: BPS.

Inskeep, Edward. 1991. Tourism Planning: An Integrated and Sustainable Development Approach. New York: Van Nostrand Reinhold

International Council on Monuments and Sites (ICOMOS). Tanpa Tahun. International Charter for the Conservation and Restoration of Monuments and Sites. Paris: ICOMOS.

Kasali, Rhenald. 2000. Manajemen Periklanan: Konsep dan Aplikasinya di Indonesia. PT. Pustaka Utama Grafiti. Jakarta.

Kementerian Kebudayaan dan Pariwisata Republik Indonesia. 2009. UU RI No.10 Tahun 2009 tentang Kepariwisataan, Jakarta: Kemenbudpar

Kotler P, Bowen J.T, Makens J.C. 2004. Marketing for Hospitality and Tourism. Upper Saddle River, New Jersey, 07458: Pearson Education, Inc

Kotler, Philip \& Armstrong, Gary. 2004. Prinsip-prinsip Pemasaran. Edisi Keduabelas. Erlangga. Jakarta.

Kotler, Philip and Gary Armstrong. 1991. Principle of Marketing. Fifth edition. New Jersey: Prentice-Hall Inc.

Kotler, Philip. 2003. Manajemen Pemasaran. Edisi Kesebclas, Jakarta: Indeks kelompok Gramedia.

Kotler, Philip, dkk. 2005. "Fourth European Edition Principle of Marketing". England: Prentice Hall.

Macionis, John. J. 1996. Sociology Fifth Edition. Prentice-Hall International, Inc

McIntosh, R. dan Goeldner, C. 1990. Tourism Principles, Practices, Philosophies. New York: Jhon Wiley and Sons Inc.

Pitana, I Gede. 2005. Sosiologi Pariwisata, Kajian Sosiologis terhadap Struktur, Sistem, dan Dampakdampak Pariwisata. Yogyakarta: Andi Offset.

Prasetijo \& Risyanti, dan John J.O.I. Ihalauw, Perilaku Konsumen. Yogyakarta: Penerbit Andi, 2000

Samsuridjal, D. 1997. Peluang di Bidang Pariwisata. PT. Mutiara Sumber Widya Sugiyono, 1997. Statistika Untuk Penelitian, Bandung: Alfabeta 2000. Metode Penelitian Bisnis. Bandung: Alfabeta.

Sukarsa, I Made. 1994. Pengantar Pariwisata. Departemen Pendidikan dan Kebudayaan 
Direktorat Jenderal Pendidikan Tinggi Badan Ketjasama Perguruan Tinggi Negeri Indonesia Timur.

Swarbrooke, J. 1996. Sustainable Tourism Management. New York: CABI Publishing is division of CAB International.

Swarbrooke, John. 1995. The Development and Management of Visitor Attractions. United Kingdom.

Wahab, Salah. 2003. Tourism Management. London: Tourism International Press.

Wardiyanta, M. 2006. Metode Penelitian Pariwisata. Yogyakarta: ANDI.

Winarno, Surakhmad. 1985. Pengantar Penelitian Ilmiah: Dasar dan Teknik. Bandung: Tarsito. 